\title{
Article \\ Chronic Pulmonary Aspergillosis Situation among Post Tuberculosis Patients in Vietnam: An Observational Study
}

\author{
Ngoc Thi Bich Nguyen ${ }^{1, *}$, Huy Le Ngoc ${ }^{1, *}$ (D) Nhung Viet Nguyen ${ }^{1}$, Luong Van Dinh ${ }^{1}$, Hung Van Nguyen ${ }^{1}$, \\ Huyen Thi Nguyen ${ }^{1}$ and David W. Denning $2,3, * \mathbb{D}$ \\ 1 Vietnam National Lung Hospital, Hanoi 10000, Vietnam; vietnhung@yahoo.com (N.V.N.); \\ dinhvanluong66@gmail.com (L.V.D.); hungmtb75@gmail.com (H.V.N.); \\ huyennguyen0406@gmail.com (H.T.N.) \\ 2 Manchester Academic Health Science Centre, Faculty of Biology, Medicine and Health, \\ University of Manchester, Manchester M23 9LT, UK \\ 3 Global Action Fund for Fungal Infections, 1208 Geneva, Switzerland \\ * Correspondence: ngocn4@hotmail.com (N.T.B.N.); huy.lengochmu@gmail.com (H.L.N.); \\ ddenning@manchester.ac.uk (D.W.D.)
}

check for updates

Citation: Nguyen, N.T.B.; Le Ngoc, H.; Nguyen, N.V.; Dinh, L.V.; Nguyen, H.V.; Nguyen, H.T.; Denning, D.W. Chronic Pulmonary Aspergillosis Situation among Post Tuberculosis Patients in Vietnam: An Observational Study. J. Fungi 2021, 7, 532. https://doi.org/10.3390/ jof7070532

Academic Editor: David S. Perlin

Received: 23 April 2021

Accepted: 28 June 2021

Published: 30 June 2021

Publisher's Note: MDPI stays neutral with regard to jurisdictional claims in published maps and institutional affiliations.

Copyright: (c) 2021 by the authors. Licensee MDPI, Basel, Switzerland. This article is an open access article distributed under the terms and conditions of the Creative Commons Attribution (CC BY) license (https:// creativecommons.org/licenses/by/ $4.0 /)$.

\begin{abstract}
This study provides a brief view of chronic pulmonary aspergillosis (CPA) in the posttuberculosis treatment community in Vietnam, a high burden tuberculosis (TB) country. In three months in late 2019, 70 post-TB patients managed at Vietnam National Lung Hospital were enrolled. Of these, 38 (54.3\%) had CPA. The male/female ratio was 3/1 (28 males and ten females). CPA patients had a mean age of $59 \pm 2.3$ years (95\%CI 54.4-63.6). The mean Body mass index (BMI) was $19.0 \pm 0.5(18.0-20.0)$ and 16 of 38 (42.1\%) patients had concurrent diseases, the most common of which were chronic obstructive pulmonary disease (COPD) and diabetes. Twenty-six patients (68.4\%) developed hemoptysis, 21 (55.3\%) breathlessness, and weight loss was seen in 30 (78.9\%). Anaemia was seen in $15(39.5 \%)$ and 27 of $38(71.1 \%)$ patients had an elevated C-reactive protein (CRP). The most common radiological findings were multiple cavities $(52.6 \%)$ and pleural thickening $(42.7 \%)$, followed by aspergilloma (29.0\%) and non-specific infiltrates. There were five of 38 patients (13.2\%) with a cavity containing a fungal ball on the chest X-ray, but when the high resolution computed tomography (HRCT) was examined, the number of patients with fungal balls rose to $11(28.9 \%)$. Overall, 34 of $38(89.5 \%)$ cases had an elevated Aspergillus IgG with an optical density $\geq 1$, and in 2 cases, it was $0.9-1.0(5 \%)$, borderline positive. In nine patients (23.7\%) Aspergillus fumigatus was cultured from sputum. CPA is an under-recognised problem in Vietnam and other high burden TB countries, requiring a different diagnostic approach and treatment and careful management. HRCT and Aspergillus IgG serum test are recommended as initial diagnostic tools for CPA diagnosis.
\end{abstract}

Keywords: chronic pulmonary Aspergillosis; prior tuberculosis; Vietnam; developing countries

\section{Introduction}

TB remains a worldwide health problem with complicated sequelae even after the end of treatment [1]. Among TB sequelae, chronic pulmonary aspergillosis (CPA) is the most deadly chronic sequela with multiple presentations [2]. CPA can supervene in many respiratory diseases, including chronic obstructive pulmonary disease (COPD), asthma, and cystic fibrosis, affecting an estimated 3 million people. TB and probably COPD patients are the most common predisposing conditions. About one among five post-TB patients with a cavity will develop CPA after treatment [3].

This disease silently destroys lung parenchyma with progressive cavitation, pleural thickening, and fibrosis. The usual lack of specific symptoms and a definitive diagnostic test leads to high mortality rates, even higher with antifungal drug resistance $[4,5]$.

In limited resources settings and high burden TB countries, CPA diagnosis is commonly confused with other diseases, such as smear-negative TB. These errors lead to 
harmful problems in both clinical and epidemiological settings: the slow process of diagnosis and treatment, low treatment adherence, and poor outcomes increases the public health risk of developing multidrug-resistant TB because of lack of confidence in TB services, and waste of healthcare resources [5]. Hence, a good approach and understanding of the disease are essential, especially in high burden TB countries [6].

Vietnam is ranked 13th among 30 high burden TB countries [1]. Previous studies have reported a high burden of fungal infections and also antifungal drug resistance [7]. Despite these complications, direct CPA data are lacking in Southeast Asia and Vietnam. Hence, we conducted a study with two objectives: to describe the CPA situation among post TB patients and to evaluate the prognostic factors of having CPA after PTB, to give a preliminary view of CPA in Vietnam, a tropical country with a high TB burden and limited laboratory diagnostics for fungal disease.

\section{Materials and Methods}

\subsection{Patients}

A retrospective observational study was conducted with medical records of patients at Vietnam National Lung Hospital from October 2019 to December 2020. All the patients were diagnosed based on international guidelines from the European Society for Clinical Microbiology and Infectious Diseases and the European Respiratory Society [2,8].

All patients with a history of prior TB therapy who presented with abnormal radiological findings and prolonged respiratory symptoms were recruited for this study. The patients were diagnosed with CPA if they had the following criteria: (i) presenting with clinical features such as prolonged cough, weight loss, bronchiectasis, or hemoptysis lasting for at least three months; (ii) radiological findings suggesting any features of CPA, including aspergilloma, cavity, multiple cavities, pericavitary infiltrates, thickened pleura or fibrosis [9]; (iii) serological or microbiological evidence implicating Aspergillus spp. or histopathological evidence [10].

We excluded patients with either a history of having antifungal treatment in the last two months before the clinical review or active TB.

\subsection{Clinical Samples and Radiological Findings}

Respiratory specimens, including bronchoalveolar lavages (BAL) and sputum, were cultured and followed a standard protocol provided by our Vietnam National Reference TB Laboratory, located in our hospital, to ensure quality handling. The description of our National Reference Laboratory center can be found elsewhere [11].

Positive culture for Aspergillus sp. from a respiratory sample (BAL, sputum) and histopathology confirmed were taken as solid evidence of CPA. All patients were also tested for Mycobacteria spp. using GeneXpert or culture in sputum and BAL to exclude any TB relapse.

All the patients were screened with a chest X-ray and also had a high solution computed tomography (CT) scan of the thorax. An expert panel interpreted the chest X-rays and CT scans with experienced pulmonologists and radiologists for consensus on the characteristic features of CPA or other conditions.

\subsection{Serology Test}

We tested serum IgG Aspergillus antibodies in all the patients using the Aspergillus fumigatus IgG ELISA (enzyme immunoassay (EIA)) (Bordier Affinity Products, Switzerland). The specimens' investigation was done as per the manufacture's recommendations with an optical density (OD) cut-off of 1 for a positive IgG serum level. Moreover, we analyzed with the cut-off $O D$ value of 0.9 to find differences between the IgG serum levels [12]. 


\subsection{Treatment}

CPA treatment followed international guidelines ( $400 \mathrm{mg}$ oral itraconazole ( 2 capsules) daily after a meal for at least six months in those who agreed to take it. We have not collected follow-up data on response (a future study).

\subsection{Statistical Analysis}

We used the STATA ${ }^{\circledR}$ version 13 (STATA, College Station, TX, USA) for data management and analysis. The demographic and other features were analyzed by descriptive analysis with mean, median, and percentages. All the tests with a $p$-value $<0.05$ were considered significant.

\subsection{Ethical Issues}

This study was approved by the Vietnam National Lung Hospital Ethical Committee and all the recruited patients signed a consent form before study enrollment.

\section{Results}

In total, 70 patients were referred to our hospital because of respiratory symptoms, having been treated for TB previously. Among them, 40 (56.7\%) patients were diagnosed with CPA. Two CPA patients with active TB were excluded. Finally, we had 38 CPA patients with a history of prior TB. The male/female ratio was $3 / 1$ (28 males and 10 females). CPA patients had a mean age of $59 \pm 2.29$ years (95\%CI 54.35-63.64) (minimum 22 years and maximum 86 years). Mean BMI was $18.98 \pm 0.496$ (17.97-19.98). For comorbidities, 16/38 $(42.1 \%)$ patients had concurrent diseases. The most common were COPD and diabetes (Table 1). Several patients had bronchiectasis (three cases). Cultures for Mycobacteria were negative for all species, other than the two excluded above.

Table 1. The demographic, clinical symptoms, and radiological findings of CPA patients.

\begin{tabular}{|c|c|c|}
\hline Features & No. & Statistics \\
\hline \multicolumn{3}{|c|}{ Baseline demographics } \\
\hline CPA confirmed cases & 40 & \\
\hline Age mean (SD)/Median (IQR) & 59 & $2.3(54.4-63.6)$ \\
\hline Males & 28 & $73.7 \%$ \\
\hline Females & 10 & $26.3 \%$ \\
\hline BMI & 19.0 & $0.49(18.0-20.0)$ \\
\hline \multicolumn{3}{|c|}{ Comorbidities } \\
\hline Diabetes & 5 & $12.5 \%$ \\
\hline COPD & 8 & $20 \%$ \\
\hline Bronchiectasis & 3 & $7.5 \%$ \\
\hline \multicolumn{3}{|c|}{ Interval after $\mathrm{TB}$ to $\mathrm{CPA}$ presentation } \\
\hline$<5$ years & 9 & $27.3 \%$ \\
\hline $5-10$ years & 10 & $30.3 \%$ \\
\hline$>10$ years & 14 & $42.4 \%$ \\
\hline \multicolumn{3}{|c|}{ Clinical symptoms } \\
\hline Cough & 37 & $97.4 \%$ \\
\hline Productive cough & 31 & $81.6 \%$ \\
\hline Hemoptysis & 18 & $47.4 \%$ \\
\hline Dyspnea & 21 & $55.3 \%$ \\
\hline
\end{tabular}


Table 1. Cont.

\begin{tabular}{ccc}
\hline Features & No. & Statistics \\
\hline Fever & 8 & $21.1 \%$ \\
\hline Weight loss & 14 & $36.8 \%$ \\
\hline Chest X-ray radiological findings & \\
\hline Cavitary lesion & 8 & $21.1 \%$ \\
\hline Aspergilloma & 5 & $13.2 \%$ \\
\hline Pleural thickening & 30 & $79.0 \%$ \\
\hline Hemithorax & 5 & $21.1 \%$ \\
\hline Bilateral & Chest CT findings & \\
\hline Left & 19 & $50.0 \%$ \\
\hline Right & 7 & $18.4 \%$ \\
\hline Multiple cavities with thickened pleura & 12 & $31.6 \%$ \\
\hline Fungal ball(s) (aspergilloma) & 20 & $52.6 \%$ \\
\hline Single cavity with thickened pleura & 11 & $28.9 \%$ \\
\hline Pleural thickening & 6 & $15.8 \%$ \\
\hline Bronchiectasis & 17 & $44.7 \%$ \\
\hline Non-specific infiltrates & 10 & $26.3 \%$ \\
\hline
\end{tabular}

Ten patients had been treated for recurrent TB once, and three patients had been treated for TB three times. Remarkably, 14 of $33(42.4 \%)$ patients had a history of being treated for TB more than 10 years previously and $12(30.3 \%) 5-10$ years previously. Twothird of CPA patients had previously treated TB more than seven years previously (the longest time is 31 years).

Productive cough was the primary symptom noticed in nearly $100 \%$ of patients in this study, often with mucus production $(n=37(97.4 \%))$. Twenty-six patients $(68.42 \%)$ developed hemoptysis, 21 (55.3\%) breathlessness, and weight loss was seen in 30 (78.9\%). Anaemia was seen in about a third of patients-15 (39.5\%).

Culture grew Aspergillus fumigatus in 10 cases, six in sputum, and four from BAL specimens. No other species were found. Histopathology findings were characteristic of CPA in three patients who underwent lung lobectomy and the other two who had transthoracic lung biopsies.

Overall, 27 of the 38 (71.1\%) patients had an elevated C-reactive protein (CRP) (Table 2). All patients were tested for Aspergillus IgG (Table 2).

Table 2. The laboratory parameters of CPA patients.

\begin{tabular}{cccc}
\hline Blood Test & Mean/Median & SD/IQR & Normal Range \\
\hline WBC & 10.6 & 4.9 & $4.5-11.0$ \\
\hline CRP & 60.9 & 71.7 & $0-5.0$ \\
\hline Aspergillus IgG & 2.82 & 1.9 & $<0.9$ \\
\hline
\end{tabular}

Overall, 34 of 38 (89.5\%) cases had an Aspergillus IgG optical density $\geq 1$, and in four cases, IgG was less than $1(10.5 \%)$. The mean IgG OD was $2.82 \pm 1.9$. There were four cases with an Aspergillus IgG $<1$. One case had lung lobectomy, so confirmed histopathologically. Others were confirmed with Aspergillus in sputum and BAL culture (in one case, the Aspergillus IgG OD was 0.978 , and two others were 0.482 and 0.738 ). If the OD threshold was reduced to 0.9 , two more cases were defined as CPA using serology (94.7\%) (Figure 1). 


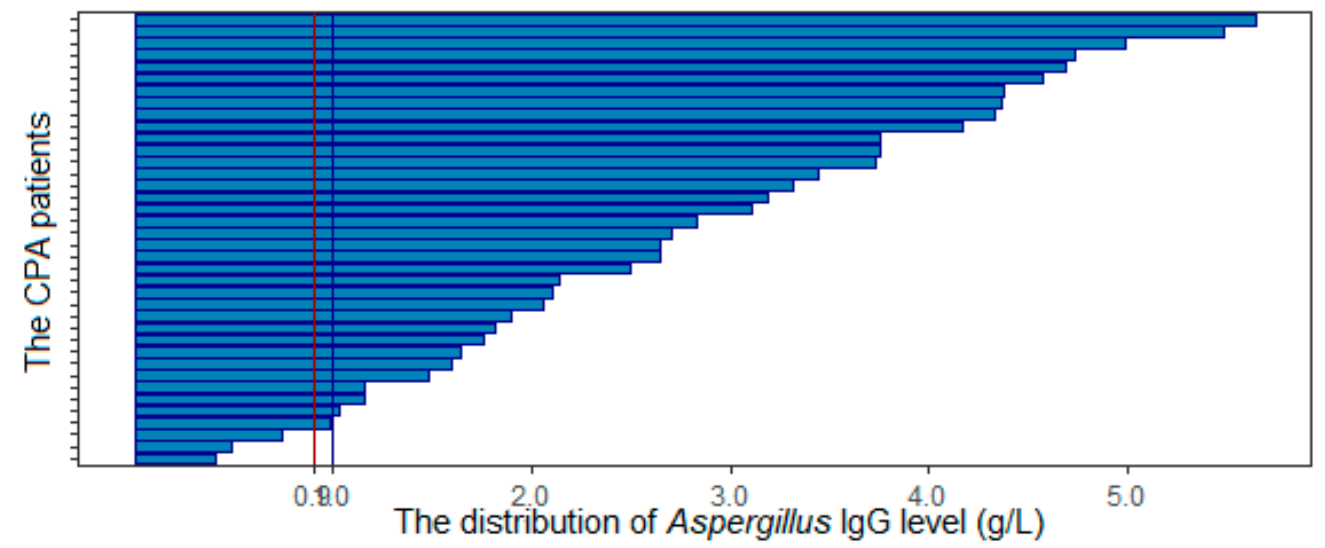

Figure 1. Summary of Aspergillus IgG distribution.

We found a slight correlation between the duration of TB infection and Aspergillus IgG levels ( $p$-value $=0.005)$ (Figure 2). However, the R squared is low $(0.01)$, indicating that the height of the Aspergillus IgG antibody response is only slightly influenced by time.

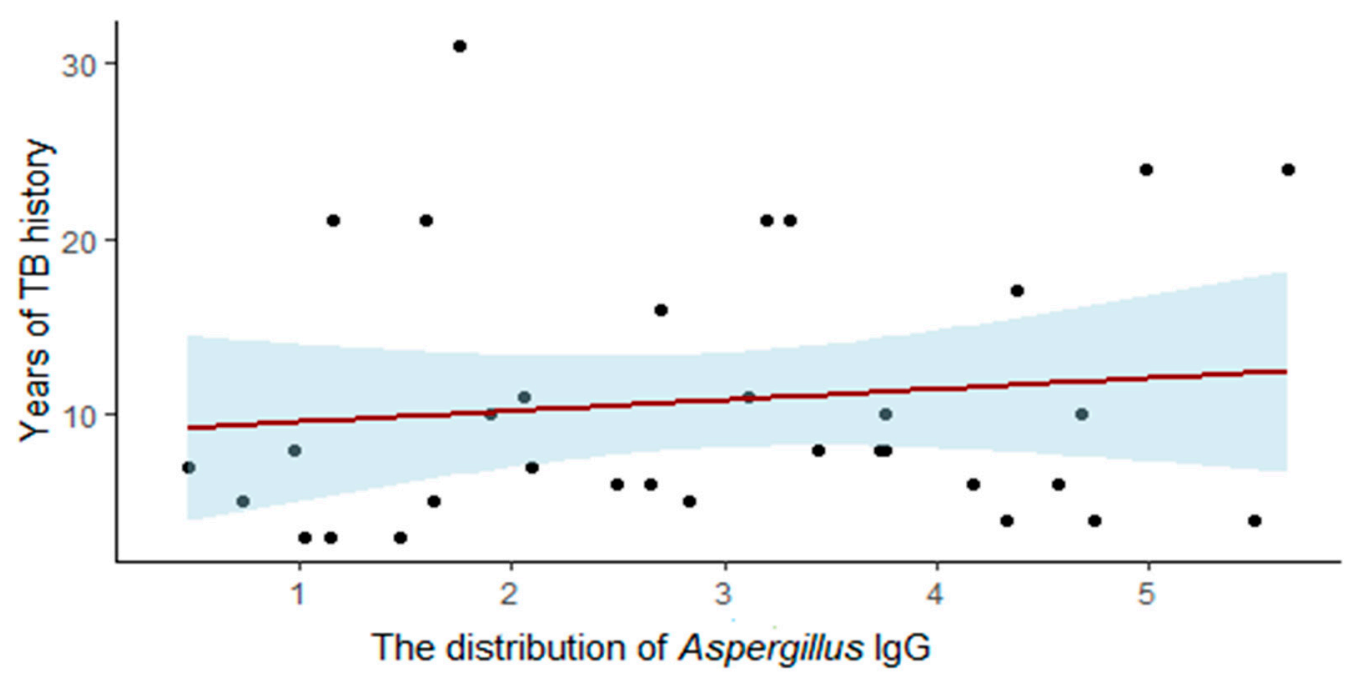

Figure 2. The correlation between Aspergillus IgG level and years of TB history.

With regard to the radiological findings, half of the patients had bilateral damage, $31.9 \%$ had damage on the right side, and the remainder only on the left. The most common findings were multiple cavities (52.6\%) and pleural thickening (42.7\%), followed by aspergilloma $(29.0 \%)$ and infiltrates. Five of the 38 patients $(13.2 \%)$ had a cavity containing a fungal ball on the chest X-ray, but when the HRCT was examined, the number of patients with fungal balls rose to $11(28.9 \%)$. (Figure 3$)$. 

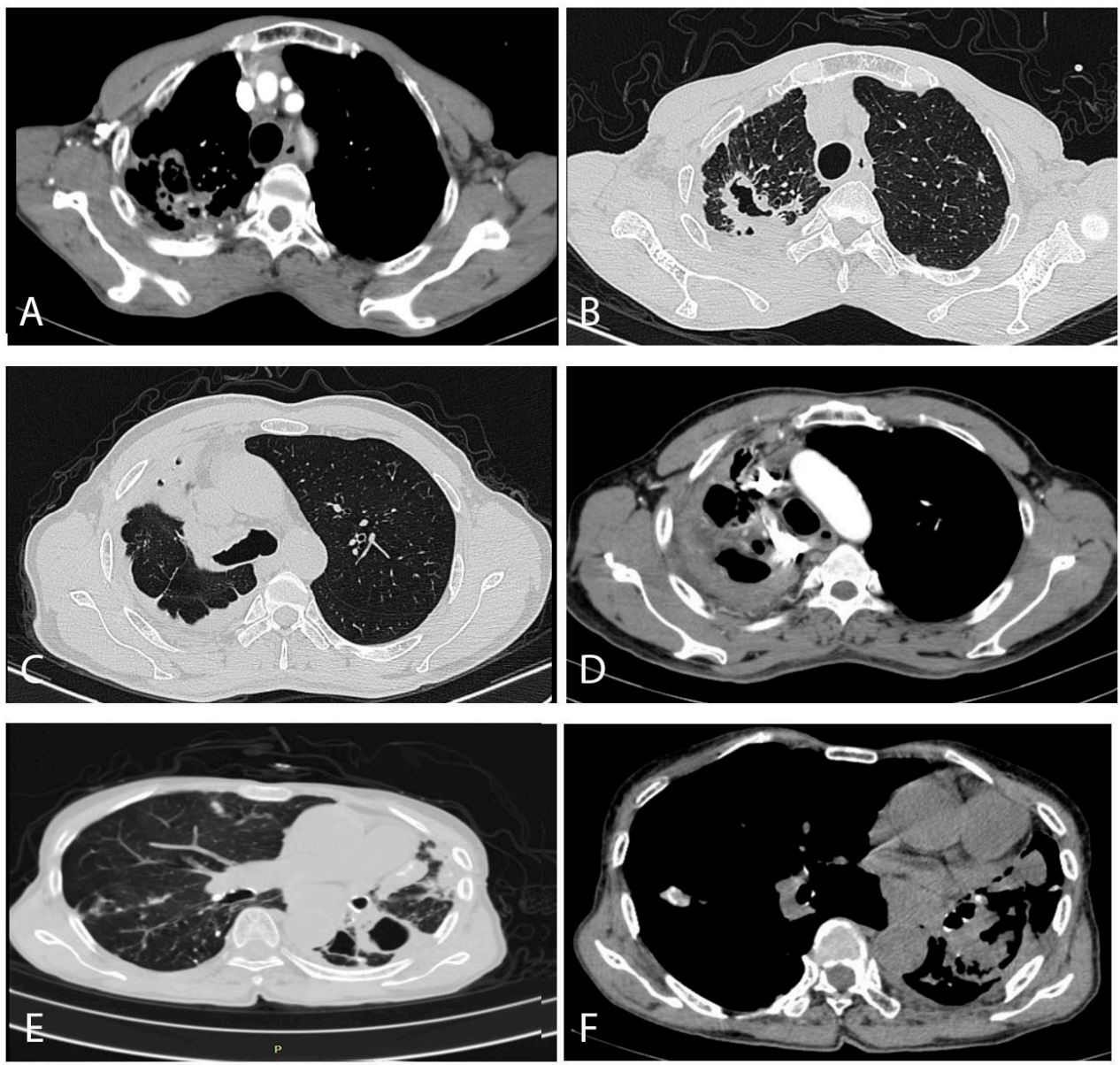

Figure 3. Typical computed tomography findings in our CPA patients. (A,B) were from a 71-year-old male patient, (C,D) were of a 50-year-old male patient, and (E,F) were from a 78-year-old female patient. (A) (contrast enhanced scan) shows enlarged arterial vessels on the edge of two separate cavities posteriorly in the right lung. The lung windows from a slightly higher section show a large thick-walled cavity with an irregular interior lining, and probably three other much smaller cavities, in association with remarkable pleural thickening posteriorly, with some pleural fat lateroposteriorly. No aspergilloma is visible in either image. (C) shows extensive pleuro-pulmonary fibrosis encasing the right upper lung, with two small cavities (probably) anteriorly. The right main bronchus and mediastinum is shifted to the right. In (D), slightly higher in the chest at the level of the aortic arch, shows considerable major arterial blood vessel distortion, additional enlarged arteries within the areas of inflammation or fibrosis and an anterior cavity. (E) shows at least one thick-walled cavity at the top of the left overlying an area of significant pleural thickening, with areas of consolidation or fibrosis anteriorly, containing some calcification on a bullous emphysematous background. There is a small area of ill-defined inflammation in the right lung. The bronchial walls contain significant calcification. (F) also shows the major mediastinal shift to the left, with extensive areas of consolidation or fibrosis with no particular pattern.

Following evaluation in clinic, and with all the results available to treating physicians, $21(55.2 \%)$ patients were treated with itraconazole therapy. However, we did not collect follow-up information.

\section{Discussion}

CPA is a complicated pulmonary syndrome that requires a careful approach in diagnosis, treatment, and management. This is the first descriptive study from Vietnam to provide a brief view of the clinical spectrum and associated factors of CPA in the post-TB population. A recent attempt to quantify the likely prevalence of CPA in Vietnam estimated 55,500 
affected people, 61 per 100,000, which is an internationally high rate. Post-tuberculous cavitation is common in Vietnam at $41 \%$ [13-15].

In this study, we highlighted the features/clinical symptoms of CPA among posttuberculosis patients. This is the first study to describe the characteristics of CPA among the post-TB community in Southeast (SE) Asia. This study provides essential material for developing a national guideline for diagnosing, treating, and managing CPA.

Most of the patients we identified with CPA were older than 50 , mean age $59 \pm 2.25$ years. This is similar to other studies, where CPA is most often reported mostly in middle-aged patients. In a previous study, age has been reported as a risk factor for poor outcomes in CPA TB patients [16]. The link with older age may be partially explained by the chronic development of CPA [3], but some comorbidities were also found; $10 \%$ of our patients had at least one comorbidity, mostly COPD or diabetes. Diabetes has been described as a significant association with CPA, as reported in several previous studies [16-18]. Diabetes is also considered a risk factor for developing a cavity during pulmonary TB and may be a risk factor for developing CPA [19-21]. In low-burden TB countries, other common risk factors are COPD and prior pulmonary surgery history $[19,22]$. However, in our study, only $20 \%$ of CPA patients had a COPD history. With a COPD prevalence of $6.7 \%$ and a population of 100 million [23], it is also essential to consider CPA as a differential diagnosis for TB among COPD patients in Vietnam. A holistic approach and screening for comorbidities in CPA patients is also required.

Furthermore, when screening people with a history of prior $\mathrm{TB}$, we found two patients with positive TB tests who had concurrent CPA. Even with the exclusion of these patients due to the mimicking of symptoms and radiological findings, this interesting finding indicates that Aspergillus and Mycobacterium can combine to damage the lung. Hedayati in Iran and Iqbal in Pakistan reported that $13.7 \%$ and $13 \%$ of patients with CPA were co-infected with $M$. tuberculosis, respectively $[18,24]$.

Hence, we recommend that every patient with PTB, active or with a prior history, should be screened for CPA to prevent the possibility of having a co-infection, especially if symptoms persist despite anti-tuberculous therapy.

Our data should raise awareness of CPA and the need to consider other respiratory diseases with similar non-specific symptoms. CPA is being underestimated and often confused with another chronic pulmonary disease, especially smear-negative TB [2]. The years of misdiagnosis of tuberculosis and incorrect treatment is addressable with clinical training and testing for fungal disease and aspergillosis.

In our study among post-TB patients, $56.7 \%$ were found to have only CPA and $2.9 \%$ had CPA and PTB, using criteria proposed for low resource settings [2]. This result is higher than similar studies in Uganda [6,25]. It can be explained by our small sample size. Globally, the prevalence of CPA among post TB patients ranged from $21-35 \%$, depending on country situation [25]. What we cannot know is how many patients died of CPA, misdiagnosed as TB, and therefore could not have been referred for evaluation. The cohort seen in our center are probably the 'slow progressors', and much more aggressive CPA is likely to have been fatal [26].

Most of the CPA patients we identified developed CPA at least two years after treatment for PTB. The history of TB treatment is discussed in other studies [18]. Previous studies have reported higher percentages of having CPA after PTB treatment than patients just finishing complete therapy [3]. CPA development over time can explain this even after TB treatment. The interval between completing TB therapy and development of CPA is often many years. Suspicion and early diagnosis of CPA is important as five-year mortality rates are $50 \%$ even with treatment [2].

Prolonged cough with mucus and hemoptysis are the most common symptoms of CPA, followed by weight loss and fever [27]. Although cough and hemoptysis are typical, they are not reliable symptoms alone for CPA diagnosis as several other conditions including bronchiectasis and PTB have these manifestations. Symptoms lasting longer than three 
months is a clue for clinicians to think about CPA [2,12]. Otherwise, progression and death are common $[28,29]$.

A CT scan is recommended as an initial diagnostic aid tool when CPA is clinically considered, providing better and more precise information than X-rays [30-32]. Over 50\% of our patients had bilateral damage, and right-sided damage is more common than the left, consistent with the TB damage.

Unlike invasive pulmonary aspergillosis in which the specific halo sign can often be seen, the CPA radiological findings include aspergilloma, multiple cavities, and pleural thickening or necrotizing development [33]. Radiographic CT scan features secondary to Aspergillus infection range from a typical appearance of a fungus ball within the lung cavity to complex pleuro-parenchymal features related to the progressive destructive cavitary disease. Our study's most common manifestation was multiple cavities, similar to other reviews $[12,34]$. Typical radiological findings have been described elsewhere $[35,36]$. It is difficult to distinguish CPA from other cavitary diseases such as tuberculosis, chronic cavitary pulmonary histoplasmosis, bronchiectasis, or even a combination of these conditions. In a few select cases, when Aspergillus develops into a fungal ball in a cavity, we can see an unusual type of CPA with a cavity with a crescent moon inside surrounding a fungal ball [35].

The role of Aspergillus IgG has been reported in previous studies [2,3,37]. This test is often considered the gold standard test for CPA diagnosis and is valuable for tracking the disease's progression with a high positive predictive value [11,22]. In an Indonesian study, the Aspergillus IgG was a convenient tool with good diagnostic performance and simple application [3]. In most studies, Aspergillus IgG is positive in $80-92 \%$ of CPA cases, and we had two false negative tests in our patients.

An approach using clinical symptoms and Aspergillus IgG would be the initial screen for diagnosing CPA $[38,39]$. Our study also found a high level of $\operatorname{IgG}$ associated with a history of prior PTB, similar to previous studies, where active TB patients do not have an elevated IgG level [17]. As CPA can silently develop after completion of TB treatment, annual CPA evaluation including Aspergillus IgG to check seems appropriate.

Some of our patients were treated with antifungals: $400 \mathrm{mg}$ itraconazole daily following international guidelines. This treatment is effective in some studies [40]. However, nearly half of the CPA patients did not receive any specific treatment. Our clinicians are poorly educated when approaching CPA patients, hence the poor uptake of self-funded antifungal therapy. More education and a national guideline is needed to raise the alertness of clinicians about fungal diseases.

Furthermore, in our country setting, a question arises about the azole-resistant situation since Justin Bearsley reported an extraordinary prevalence of drug-resistant Aspergilli in Vietnam [5]. Further studies should evaluate the frequency and risk of azole-resistance in the future.

Our study has some limitations. We only conducted a retrospective study, which had limited information and may suffer from recall bias. Another problem is the small number of patients, which may not be generalizable across the country. However, this study could be considered a cornerstone, along with previous studies, to raise awareness and improve clinical practice of CPA among the PTB community. Further research on the CPA situation in Vietnam is necessary to address potential problems such as drug-resistance in fungi.

Author Contributions: Conceptualization, N.T.B.N., D.W.D., H.L.N. and N.V.N., methodology, H.V.N., N.V.N., and H.T.N., validation, N.T.B.N., L.V.D., H.L.N. and H.T.N.; formal analysis, N.T.B.N. and H.L.N.; investigation, N.T.B.N. and H.T.N.; writing-original draft preparation, N.T.B.N. and H.L.N.; writing-review and editing, D.W.D., N.V.N. and L.V.D. All authors have read and agreed to the published version of the manuscript.

Funding: This research received no external funding. 
Institutional Review Board Statement: The study was conducted according to the guidelines of the Declaration of Helsinki, and approved by the local Ethics Committee of Vietnam National Lung Hospital (559/2020/NCKH).

Informed Consent Statement: Informed consent was obtained from all subjects involved in the study.

Acknowledgments: The authors are thankful to the doctors at Vietnam National Lung Hospital for their kind support in patient recruitment and management.

Conflicts of Interest: The authors declare no conflict of interest.

\section{References}

1. World Health Organization. Global Tuberculosis Report 2019; World Health Organization: Geneva, Switzerland, 2019; ISBN 978-924-156571-4.

2. Denning, D.W.; Cadranel, J.; Beigelman-Aubry, C.; Ader, F.; Chakrabarti, A.; Blot, S.; Ullmann, A.J.; Dimopoulos, G.; Lange, C. European Society for Clinical Microbiology and Infectious Diseases and European Respiratory Society Chronic pulmonary aspergillosis: Rationale and clinical guidelines for diagnosis and management. Eur. Respir. J. 2016, 47, 45-68. [CrossRef]

3. Rozaliyani, A.; Rosianawati, H.; Handayani, D.; Agustin, H.; Zaini, J.; Syam, R.; Adawiyah, R.; Tugiran, M.; Setianingrum, F.; Burhan, E.; et al. Chronic Pulmonary Aspergillosis in Post Tuberculosis Patients in Indonesia and the Role of LDBio Aspergillus ICT as Part of the Diagnosis Scheme. J. Fungi 2020, 6, 318. [CrossRef]

4. Harries, A.D.; Dlodlo, R.A.; Brigden, G.; Mortimer, K.; Jensen, P.; Fujiwara, P.I.; Castro, J.L.; Chakaya, J.M. Should we consider a "fourth 90" for tuberculosis? Int. J. Tuberc. Lung Dis. 2019, 23, 1253-1256. [CrossRef]

5. Beardsley, J.; Denning, D.W.; Chau, N.V.; Yen, N.T.B.; Crump, J.A.; Day, J.N. Estimating the burden of fungal disease in Vietnam. Mycoses 2015, 58 (Suppl. 5), 101-106. [CrossRef] [PubMed]

6. Bongomin, F.; Kwizera, R.; Atukunda, A.; Kirenga, B.J. Cor pulmonale complicating chronic pulmonary aspergillosis with fatal consequences: Experience from Uganda. Med. Mycol. Case Rep. 2019, 25, 22-24. [CrossRef]

7. (PDF) Unprecedented Prevalence of Azole-Resistant Aspergillus Fumigatus Identified in the Environment of Vietnam, with Marked Variability by Land Use Type. Available online: https://www.researchgate.net/publication/346424769_ Unprecedented_Prevalence_of_Azole-Resistant_Aspergillus_fumigatus_Identified_in_the_Environment_of_Vietnam_with_ Marked_Variability_by_Land_Use_Type (accessed on 11 March 2021).

8. Diagnosis and Management of Aspergillus Diseases: Executive Summary of the 2017 ESCMID-ECMM-ERS Guideline-Clinical Microbiology and Infection. Available online: https:/ /www.clinicalmicrobiologyandinfection.com/article/S1198-743X(18)30051 -X/fulltext (accessed on 11 March 2021).

9. Denning, D.W.; Page, I.D.; Chakaya, J.; Jabeen, K.; Jude, C.M.; Cornet, M.; Alastruey-Izquierdo, A.; Bongomin, F.; Bowyer, P.; Chakrabarti, A.; et al. Case Definition of Chronic Pulmonary Aspergillosis in Resource-Constrained Settings. Emerg. Infect. Dis. 2018, 24. [CrossRef]

10. Oladele, R.; Otu, A.A.; Olubamwo, O.; Makanjuola, O.B.; Ochang, E.A.; Ejembi, J.; Irurhe, N.; Ajanaku, I.; Ekundayo, H.A.; Olayinka, A.; et al. Evaluation of knowledge and awareness of invasive fungal infections amongst resident doctors in Nigeria. Pan Afr. Med. J. 2020, 36, 297. [CrossRef] [PubMed]

11. Le, H.N.; Sriplung, H.; Chongsuvivatwong, V.; Nguyen, N.V.; Nguyen, T.H. The accuracy of tuberculous meningitis diagnostic tests using Bayesian latent class analysis. J. Infect. Dev. Ctries. 2020, 14, 479-487. [CrossRef] [PubMed]

12. Beltrán Rodríguez, N.; San Juan-Galán, J.L.; Fernández Andreu, C.M.; María Yera, D.; Barrios Pita, M.; Perurena Lancha, M.R.; Velar Martínez, R.E.; Illnait Zaragozí, M.T.; Martínez Machín, G.F. Chronic Pulmonary Aspergillosis in Patients with Underlying Respiratory Disorders in Cuba-A Pilot Study. J. Fungi 2019, 5, 18. [CrossRef]

13. Thwaites, G.; Caws, M.; Chau, T.T.H.; D’Sa, A.; Lan, N.T.N.; Huyen, M.N.T.; Gagneux, S.; Anh, P.T.H.; Tho, D.Q.; Torok, E.; et al. Relationship between Mycobacterium tuberculosis genotype and the clinical phenotype of pulmonary and meningeal tuberculosis. J. Clin. Microbiol. 2008, 46, 1363-1368. [CrossRef]

14. Thorson, A.; Long, N.H.; Larsson, L.O. Chest X-ray findings in relation to gender and symptoms: A study of patients with smear positive tuberculosis in Vietnam. Scand. J. Infect. Dis. 2007, 39, 33-37. [CrossRef]

15. Thanh, N.P.; Khue, P.M.; Sy, D.N.; Strobel, M. Diabetes among new cases of pulmonary tuberculosis in Hanoï, Vietnam. Bull. Soc. Pathol. Exot. 1990 2015, 108, 337-341. [CrossRef]

16. Setianingrum, F.; Rozaliyani, A.; Syam, R.; Adawiyah, R.; Tugiran, M.; Sari, C.Y.I.; Burhan, E.; Wahyuningsih, R.; RautemaaRichardson, R.; Denning, D.W. Evaluation and comparison of automated and manual ELISA for diagnosis of chronic pulmonary aspergillosis (CPA) in Indonesia. Diagn. Microbiol. Infect. Dis. 2020, 98, 115124. [CrossRef] [PubMed]

17. Lee, M.-R.; Huang, H.-L.; Chen, L.-C.; Yang, H.-C.; Ko, J.-C.; Cheng, M.-H.; Chong, I.-W.; Lee, L.-N.; Wang, J.-Y.; Dimopoulos, G. Seroprevalence of Aspergillus IgG and disease prevalence of chronic pulmonary aspergillosis in a country with intermediate burden of tuberculosis: A prospective observational study. Clin. Microbiol. Infect. Off. Publ. Eur. Soc. 2020, 26, e1-e1091. [CrossRef] [PubMed]

18. Iqbal, N.; Irfan, M.; Zubairi, A.B.S.; Jabeen, K.; Awan, S.; Khan, J.A. Clinical manifestations and outcomes of pulmonary aspergillosis: Experience from Pakistan. BMJ Open Respir. Res. 2016, 3, e000155. [CrossRef] 
19. Denning, D.W.; Riniotis, K.; Dobrashian, R.; Sambatakou, H. Chronic Cavitary and Fibrosing Pulmonary and Pleural Aspergillosis: Case Series, Proposed Nomenclature Change, and Review. Clin. Infect. Dis. 2003, 37, S265-S280. [CrossRef] [PubMed]

20. Baker, M.A.; Harries, A.D.; Jeon, C.Y.; Hart, J.E.; Kapur, A.; Lönnroth, K.; Ottmani, S.-E.; Goonesekera, S.D.; Murray, M.B. The impact of diabetes on tuberculosis treatment outcomes: A systematic review. BMC Med. 2011, 9, 81. [CrossRef]

21. Iqbal, N.; Irfan, M.; Jabeen, K.; Kazmi, M.M.; Tariq, M.U. Chronic pulmonary mucormycosis: An emerging fungal infection in diabetes mellitus. J. Thorac. Dis. 2017, 9, E121-E125. [CrossRef]

22. Hayes, G.E.; Novak-Frazer, L. Chronic Pulmonary Aspergillosis-Where Are We? and Where Are We Going? J. Fungi 2016, 2, 18. [CrossRef]

23. Ngo, C.Q.; Phan, D.M.; Vu, G.V.; Dao, P.N.; Phan, P.T.; Chu, H.T.; Nguyen, L.H.; Vu, G.T.; Ha, G.H.; Tran, T.H.; et al. Inhaler Technique and Adherence to Inhaled Medications among Patients with Acute Exacerbation of Chronic Obstructive Pulmonary Disease in Vietnam. Int. J. Environ. Res. Public. Health 2019, 16, 185. [CrossRef]

24. Hedayati, M.T.; Azimi, Y.; Droudinia, A.; Mousavi, B.; Khalilian, A.; Hedayati, N.; Denning, D.W. Prevalence of chronic pulmonary aspergillosis in patients with tuberculosis from Iran. Eur. J. Clin. Microbiol. Infect. Dis. Off. Publ. Eur. Soc. Clin. Microbiol. 2015, 34, 1759-1765. [CrossRef] [PubMed]

25. Denning, D.W.; Pleuvry, A.; Cole, D.C. Global burden of chronic pulmonary aspergillosis as a sequel to pulmonary tuberculosis. Bull. World Health Organ. 2011, 89, 864-872. [CrossRef] [PubMed]

26. Tashiro, T.; Izumikawa, K.; Tashiro, M.; Morinaga, Y.; Nakamura, S.; Imamura, Y.; Miyazaki, T.; Kakeya, H.; Yamamoto, Y.; Yanagihara, K.; et al. A Case Series of Chronic Necrotizing Pulmonary Aspergillosis and a New Proposal. Jpn. J. Infect. Dis. 2013, 66, 312-316. [CrossRef]

27. Schweer, K.E.; Bangard, C.; Hekmat, K.; Cornely, O.A. Chronic pulmonary aspergillosis. Mycoses 2014, 57, 257-270. [CrossRef] [PubMed]

28. Takazono, T.; Izumikawa, K. Recent Advances in Diagnosing Chronic Pulmonary Aspergillosis. Front. Microbiol. 2018, 9, 1810. [CrossRef] [PubMed]

29. Jewkes, J.; Kay, P.H.; Paneth, M.; Citron, K.M. Pulmonary aspergilloma: Analysis of prognosis in relation to haemoptysis and survey of treatment. Thorax 1983, 38, 572-578. [CrossRef] [PubMed]

30. Prasad, A.; Agarwal, K.; Deepak, D.; Atwal, S.S. Pulmonary Aspergillosis: What CT can Offer Before it is too Late! J. Clin. Diagn. Res. JCDR 2016, 10, TE01-TE05. [CrossRef] [PubMed]

31. Gotway, M.B.; Dawn, S.K.; Caoili, E.M.; Reddy, G.P.; Araoz, P.A.; Webb, W.R. The radiologic spectrum of pulmonary Aspergillus infections. J. Comput. Assist. Tomogr. 2002, 26, 159-173. [CrossRef]

32. Godet, C.; Laurent, F.; Bergeron, A.; Ingrand, P.; Beigelman-Aubry, C.; Camara, B.; Cottin, V.; Germaud, P.; Philippe, B.; Pison, C.; et al. CT Imaging Assessment of Response to Treatment in Chronic Pulmonary Aspergillosis. Chest 2016, 150, 139-147. [CrossRef]

33. Maghrabi, F.; Denning, D.W. The Management of Chronic Pulmonary Aspergillosis: The UK National Aspergillosis Centre Approach. Curr. Fungal Infect. Rep. 2017, 11, 242-251. [CrossRef]

34. Clinical Features and Diagnosis of Chronic Pulmonary Aspergillosis in Chinese Patients. Available online: https://www.ncbi. nlm.nih.gov/pmc/articles/PMC5662405/ (accessed on 9 March 2021).

35. Raveendran, S.; Lu, Z. CT findings and differential diagnosis in adults with invasive pulmonary aspergillosis. Radiol. Infect. Dis. 2018, 5, 14-25. [CrossRef]

36. Page, I.D.; Byanyima, R.; Hosmane, S.; Onyachi, N.; Opira, C.; Richardson, M.; Sawyer, R.; Sharman, A.; Denning, D.W. Chronic pulmonary aspergillosis commonly complicates treated pulmonary tuberculosis with residual cavitation. Eur. Respir. J. 2019, 53, 1801184. [CrossRef]

37. Page, I.D.; Richardson, M.D.; Denning, D.W. Comparison of six Aspergillus-specific IgG assays for the diagnosis of chronic pulmonary aspergillosis (CPA). J. Infect. 2016, 72, 240-249. [CrossRef] [PubMed]

38. Li, H.; Rui, Y.; Zhou, W.; Liu, L.; He, B.; Shi, Y.; Su, X. Role of the Aspergillus-Specific IgG and IgM Test in the Diagnosis and Follow-Up of Chronic Pulmonary Aspergillosis. Front. Microbiol. 2019, 10, 1438. [CrossRef]

39. Richardson, M.D.; Page, I.D. Aspergillus serology: Have we arrived yet? Med. Mycol. 2017, 55, 48-55. [CrossRef]

40. Alastruey-Izquierdo, A.; Cadranel, J.; Flick, H.; Godet, C.; Hennequin, C.; Hoenigl, M.; Kosmidis, C.; Lange, C.; Munteanu, O.; Page, I.; et al. Treatment of Chronic Pulmonary Aspergillosis: Current Standards and Future Perspectives. Respir. Int. Rev. Thorac. Dis. 2018, 96, 159-170. [CrossRef] [PubMed] 